\title{
Demografia e direito indígena: uma leitura a partir do contexto catarinense ${ }^{*}$
}

\author{
Ana Lúcia Vulfe Nötzold \\ Clóvis Antônio Brighenti \\ Universidade Federal de Santa Catarina
}

\section{Resumo}

Tendo por base dados demográficos da população indígena no Estado de Santa Catarina a partir do início do século XX, buscaremos demonstrar que o crescimento populacional está diretamente relacionado a mudança da legislação indigenista, especialmente com a aprovação do texto constitucional de 1988. Até 1988 eram apenas 3 (três) terras reconhecidas no estado, passados 20 anos são pelo menos 17 novas terras além da revisão dos limites nas terras já existentes. Esta mudança no quadro fundiário está intimamente relacionada ao aumento populacional, seja pelo crescimento vegetativo expressivo, seja pelo reconhecimento de comunidades e grupos ignorados pelas políticas públicas até então. Se o regime tutelar existente significava confinamento territorial e perda da identidade, a autonomia conquistada projetou para uma perspectiva de reconhecimento e cidadania.

Palavra-chaves: Indígena; demografia; direito.

\begin{abstract}
Based on demographics of the indigenous population in the State of Santa Catarina from the beginning of the twentieth century, we demonstrate that population growth is directly related to change in indigenous law, especially with the approval of the constitutional text of 1988 . Until 1988 they were only three (3) land recognized in the state, after 20 years are at least 17 new lands beyond the review of limits on the existing land.

\footnotetext{
- Demography and Right Indigenous: a reading from the context Santa Catarina

' Endereço para correspondências: Universidade Federal de Santa Catarina, Centro de Filosofia e Ciências Humanas, Departamento de História, Laboratório de História Indígena, Campus Universitário,Trindade, Florianópolis, SC, 88040-900 (labhin@cfh.ufsc.br; anotzold@hotmail.com; clovisbrighenti@hotmail.com).
} 


\section{HUMANAS}

This change in the table land is closely related to population growth, because of the expressive growth, or the recognition of communities and groups ignored by public policies so far. If the existing supervisory regime meant territorial confinement and loss of identity, the autonomy gained designed for the prospect of recognition and citizenship.

Keywords: Indigenous; right; demography.

\section{Introdução}

Desquisar os povos indígenas no Brasil do ponto de vista demográfico envolve uma série de problemas difíceis de serem superados. A falta de dados precisos é sem dúvida a principal dificuldade para qualquer pesquisa nessa área. Foi somente em 1991 que o IBGE - Instituto Brasileiro de Geografia e Estatística incluiu a variável indígena em suas pesquisas. A metodologia adotada nas pesquisas demográficas seja do IBGE, da FunaiFundação Nacional do Índio ou de outras instituições públicas e privadas que atuam com a temática indígena, é múltipla e não contempla a diversidade lingüística e as especificidades da população indígena brasileira. A existência de povos ainda sem contato ou com pouco contato com a sociedade nãoindígena e a falta de reconhecimento de muitas terras ${ }^{2}$, são fatores que somam à imprecisão dos dados. Ao lado destes fatores temos que considerar as características específicas de cada povo indígena, como migrações, territorialidade, visitas, xamanismo e as formas próprias de contagem. Essas variáveis implicam em cuidados adicionais num estudo sobre demografia indígena. Porém, em realidades específicas, e para efeito quantitativo é possível termos dados precisos que possibilitam uma leitura consistente.

Tendo por base dados demográficos da população indígena no Estado de Santa Catarina a partir do início do século XX, buscaremos demonstrar que o aumento populacional indígena está relacionado ao contexto da mudança na legislação indigenista brasileira, especialmente ao atual texto constitucional aprovado em 05 de outubro de 1988.

O censo 2000 do IBGE contabilizou 14.542 indígenas em Santa Catarina, porém nem toda essa população vive em Terras Indígenas. Nosso interesse central é perceber a mudança que ocorreu na população que vive em Terras Indígenas, independente de sua situação fundiária,

\footnotetext{
${ }^{2}$ Dados do Conselho Indigenista Missionário indicam que há 224 terras sem providência administrativa em todo território nacional. Disponível em: http://www.cimi.org.br.
} 


\section{Demografia e direito indígena: uma leitura a partir do contexto catarinense Ana Lúcia Vulfe Nötzold e Clóvis Antônio Brighenti}

ao passo que o IBGE considerou a população indígena total, ou seja, incluiu os indígenas citadinos ${ }^{3}$, a partir do critério da autodeclaração, independentemente de pertencer a uma comunidade indígena.

\section{A população indígena em diferentes momentos históricos}

No estado de Santa Catarina vivem 3 povos indígenas - Kaingang e Xokleng do (Tronco Lingüístico Macro-Jê) e Guarani (Tronco Lingüístico Tupi). Até o ano de 1985 existia em Santa Catarina apenas dois Postos Indígenas: Posto Dr. Selistre de Campos instalado em 1941 na Reserva Xapecó - a Reserva Xapecó foi criada pelo governo do estado do Paraná através do Decreto $n .7$ de 18 de Junho de 1902, localizado na região Oeste, para confinar a população Kaingang, servindo também para abrigar a população Guarani que se encontrava na região; e o Posto Duque de Caxias (criado em 1914), localizado no Vale do Itajaí, meio-leste do estado, que confinava a população Xokleng conhecidos como Botocudos, e mais tarde passou a ser ocupada também por Guarani e Cafuzo.

Selecionamos algumas informações que nos ajudarão a perceber as mudanças ocorridas na população aldeada no estado durante o século XXe início do XXI:

1. Em 1914 ocorreu a "pacificação" dos Xokleng. Foram aldeados nas margens do Rio Platê cerca de 400 indígenas. No ano de 1932 o antropólogo Jules Henry (1932, apud SANTOS, 1973), registrou apenas 106 pessoas, "por terem sido vítimas de epidemias de gripe". Em 18 anos a população foi praticamente dizimada.

2. A revista do Museu Júlio de Castilhos e Arquivo Histórico do RS, em sua edição número 8 de 1957, trazia os dados relativos a população indígena nos três estados do sul do Brasil, referente ao ano de 1946. A população indígena em Santa Catarina estava assim distribuída:

- Posto Xapecó: "765 Caingangue 58 Guaraní num total de 823 pessoas"; - Posto Duque de Caxias: "258 Botocudo, total de 258 pessoas".

Portanto, segundo os dados da época, tínhamos uma população aldeada e assistida de 1.081 pessoas. Porém, constava uma observação de que havia "grande número de índios, que necessitam de assistência direta domiciliados nos toldos de ... Irani” (REVISTADO MUSEU 1957, p. 125).

\footnotetext{
${ }^{3}$ Termo empregado por HENRIQUES (2000), para referir-se aos indígenas que viviam na zona urbana de Blumenau.
} 


\section{HÜMANAS}

O Toldo de Irani, a que se refere a Revista, estava localizado onde hoje encontra-se a Terra Indígena Toldo Chimbangue, demarcada em 1985.

3. Levantamento realizado por Francisco Siqueira Fortes (1948) “Agente do Posto" Indígena Xapecó 4 registrou os seguintes dados sobre a população naquele posto:

-1942 havia 775 indígenas, dos quais 24 Guarani;

- 1944 havia 873, não menciona presença de Guarani;

- 1948 havia 905 pessoas das quais 100 eram Guarani;

Porém, outro documento, manuscrito, do Agente do Posto Xapecó, datado de 30 de novembro de 1944, detalha a população indígena por faixa etária e apresenta uma população total de 845 pessoas, diferente dos dados acima para o mesmo ano.

\section{Quadro 1}

População Kaingang e Guarani no Posto Indígena Xapecó em 1944

\begin{tabular}{c|c|c|c|c|c|c|c|c|c|c|c}
\hline & \multicolumn{4}{|c|}{ Masculinos } & \multicolumn{5}{c|}{ Feminino } & \\
\hline & $<6$ & $\mathbf{6 - 1 6}$ & $\mathbf{1 7 - 3 9}$ & $\mathbf{4 0 - 5 9}$ & $>\mathbf{6 0}$ & $<6$ & $\mathbf{6 - 1 6}$ & $\mathbf{1 7 - 3 9}$ & $\mathbf{4 0 - 5 9}$ & $>\mathbf{6 0}$ & \\
\hline Kaingang & 84 & 131 & 106 & 53 & 17 & 40 & 122 & 125 & 48 & 15 & 756 \\
\hline Guarani & 7 & 25 & 11 & 9 & 1 & 2 & 8 & 18 & 5 & 3 & 89 \\
\hline Total & 91 & 131 & 157 & 62 & 18 & 42 & 130 & 143 & 53 & 18 & 845 \\
\hline Masc/Fem & \multicolumn{3}{|c|}{459} & \multicolumn{6}{c|}{386} & & $\mathbf{8 4 5}$ \\
\hline
\end{tabular}

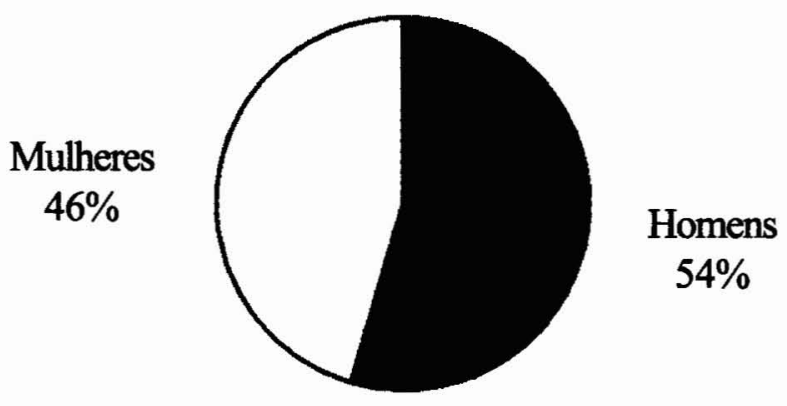

Figura 1

População masculina e feminina no Posto Indígena Xapecó em 1944

\footnotetext{
${ }^{4}$ Agente do Posto Indigena no período de 1942/1948. In: SANTOS, S. C. dos. A integração do indio na sociedade regional. A função dos Postos Indígenas em SC. Florianópolis: UFSC, 1970, p. 73.

${ }^{5}$ Anotações pessoais de Francisco Siqueira Fortes, agente do Posto Indígena Xapecó, em 30 de Novembro de 1944. Acervo SEDOC Cimi Brasília. Localizador: SC.XK.KG.4 a/30
} 
Demografia e direito indígena: uma leitura a partir do contexto catarinense Ana Lúcia Vulfe Nötzold e Clóvis Antônio Brighenti

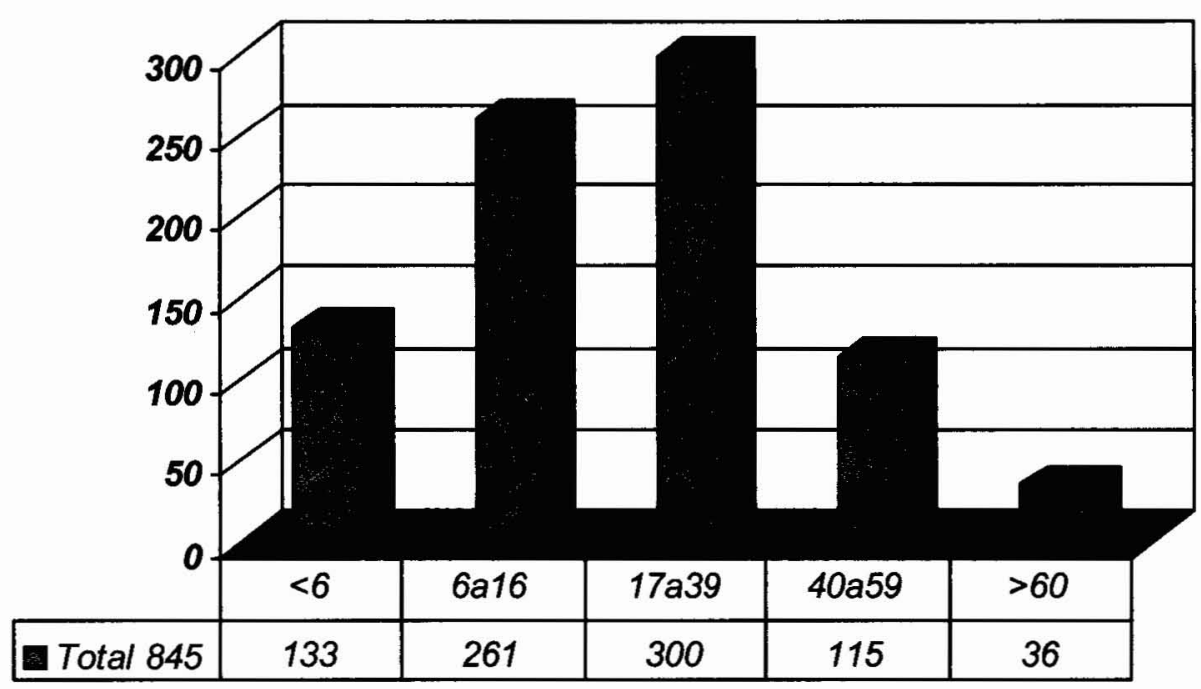

Figura 2

População por faixa etária no Posto Indígena Xapecó em 1944

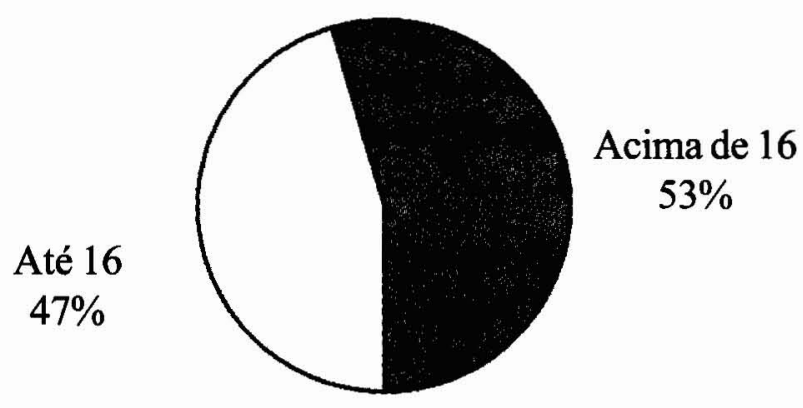

Figura 3

População por faixa etária no Posto Indígena Xapecó em 1944: > e < de 16 anos

4. Em 1951 o Inspetor da Sétima Inspetoria Regional do Serviço de Proteção aos Índios, sediado em Curitiba, Deocleciano de Souza Nenê (1951), encaminhou oficio ao governo do estado de Santa Catarina tratando da situação das duas "reservas" indígenas existentes no estado, e mencionou que no Posto Indígena Xapecó havia 900 índios, 


\section{HÜMANAS}

entre Kaingang e Guarani; e no Posto Indígena Duque de Caxias havia 250 índios botocudos. Nesse documento o inspetor se refere a mais dois locais com presença indígena que não eram assistidos pelo Serviço de Proteção ao Índio: Um grupo em Porto União com 40 botocudos; e um grupo de 50 kaingang nas margens do rio Irani. Sobre o grupo localizado nas margens do Irani o Inspetor informa ao governador que "estes o S.P.I. procurará transferir para as terras do Xapecó". Os dados acima sugerem que em 1951 a população indígena em SC era de 1.240 pessoas.

5. O informativo Luta Indígena, n. 02, do mês de Maio de 1976, informava que a população indígena no estado era de 1.785 pessoas, vivendo no Posto Indígena Ibirama - 650 pessoas; e o Posto Indígena Xapecó - 1135 pessoas (CIMI SUL, 1976).

6. No ano de 1988 a população indígena em Santa Catarina era de aproximadamente 4.700 pessoas assim distribuídas: Kaingang 3.000 pessoas; Xokleng 1.200 pessoas e Guarani 500 pessoas (CIMI SUL, 1988a).

7. Em 10 de março de 1992, ou seja, menos de 04 (quatro) anos após a promulgação do novo texto constitucional, a população indígena em Santa Catarina era de 5.235, segundo o relatório do chefe da seção de atividades produtivas da Fundação Nacional do Índio em Chapecó (DOS ANJOS, 1992).

8. Em 1998, a partir de dados da Fundação Nacional do Índio em Curitiba e do Conselho Indigenista Missionário Regional Sul, é possível concluir que havia no estado 6.180 indígenas, assim distribuídos:

- Xokleng $=1480$ (FUNAI, 1998).

- Guarani $=414$ (Idem).

- Kaingang $=4286$ (CIMI SUL, 1998).

9. Para o ano de 2008 temos um quadro mais detalhado da população que vive nas Terras Indígenas, perfazendo um total de 8.929 pessoas. 
Demografia e direito indigena: uma leitura a partir do contexto catarinense Ana Lúcia Vulfe Nötzold e Clóvis Antônio Brighenti

\section{Quadro 2}

Terras e população indígena atual ${ }^{6}$

\begin{tabular}{|c|c|c|c|c|c|c|c|c|c|c|c|c|}
\hline \multirow{2}{*}{$\begin{array}{l}\text { Terras e } \\
\text { Reservas } \\
\text { Indigenas }\end{array}$} & \multirow{2}{*}{ Povo } & \multicolumn{5}{|c|}{ Homens } & \multicolumn{5}{|c|}{ Mulheres } & \multirow{2}{*}{ Total } \\
\hline & & $<1$ & $1-4$ & $5-14$ & $15-49$ & $>49$ & $<1$ & $1-4$ & $5-14$ & $15-49$ & $>49$ & \\
\hline Toldo Imbu & $\mathrm{K}^{*}$ & 3 & 5 & 15 & 33 & 1 & 1 & 5 & 17 & 25 & 2 & 107 \\
\hline Toldo Pinhal & $\mathrm{K}$ & 1 & 2 & 16 & 23 & 9 & 2 & 3 & 19 & 18 & 7 & 100 \\
\hline Toldo Chimbangue & $\mathrm{K}$ & 2 & 16 & 62 & 97 & 24 & 2 & 20 & 55 & 91 & 21 & 390 \\
\hline Aldeia Konda & $\mathrm{K}$ & 7 & 21 & 86 & 110 & 21 & 7 & 22 & 81 & 105 & 16 & 476 \\
\hline Xapecó & $\mathrm{K}$ & 55 & 287 & 792 & 1086 & 230 & 51 & 271 & 714 & 1003 & 233 & 4.722 \\
\hline Araçai & $\mathrm{G}^{*}$ & 1 & 9 & 24 & 28 & 6 & 1 & 6 & 23 & 26 & 4 & 128 \\
\hline Limeira & $\mathrm{G}$ & 0 & 4 & 23 & 22 & 9 & 1 & 9 & 18 & 19 & 9 & 114 \\
\hline Massiambu & $\mathrm{G}$ & 1 & 8 & 2 & 2 & 1 & 1 & 7 & 6 & 5 & 1 & 34 \\
\hline Morro dos Cavalos & $\mathrm{G}$ & 2 & 9 & 22 & 18 & 4 & 1 & 6 & 17 & 19 & 1 & 99 \\
\hline M'biguaçu & $\mathrm{G}$ & 6 & 6 & 12 & 33 & 2 & 2 & 6 & 20 & 19 & 8 & 114 \\
\hline Marangatu & $\mathrm{G}$ & 0 & 13 & 18 & 21 & 5 & 2 & 6 & 13 & 24 & 3 & 105 \\
\hline Kurui'y & $\mathrm{G}$ & 2 & 6 & 8 & 10 & 2 & 1 & 2 & 8 & 11 & 3 & 53 \\
\hline Tekoha ywy dju & $\mathrm{G}$ & 1 & 3 & 1 & 2 & 1 & 2 & 1 & 2 & 7 & 1 & 21 \\
\hline Tawai & $\mathrm{G}$ & 2 & 0 & 2 & 9 & 1 & 1 & 4 & 9 & 7 & 0 & 35 \\
\hline Itanhaen & $\mathrm{G}$ & 2 & 18 & 15 & 16 & 2 & 3 & 13 & 16 & 17 & 2 & 104 \\
\hline Cambirela & $\mathrm{G}$ & 0 & 3 & 4 & 5 & 0 & 1 & 3 & 3 & 3 & 1 & 23 \\
\hline Conquista & $\mathrm{G}$ & 1 & 1 & 6 & 9 & 1 & 0 & 0 & 9 & 7 & 3 & 37 \\
\hline Jabuticabeira/yvapuru & $\mathrm{G}$ & 2 & 5 & 9 & 15 & 2 & 1 & 1 & 9 & 9 & 3 & 56 \\
\hline Morro Alto & $\mathrm{G}$ & 0 & 9 & 18 & 14 & 5 & 2 & 5 & 11 & 13 & 3 & 80 \\
\hline Pindoty & $\mathrm{G}$ & 1 & 3 & 5 & 5 & 0 & 1 & 3 & 7 & 4 & 0 & 29 \\
\hline Tarumã & $\mathrm{G}$ & 1 & 0 & 3 & 2 & 1 & 1 & 1 & 0 & 1 & 1 & 11 \\
\hline Itaju & $\mathrm{G}$ & 0 & 1 & 6 & 5 & 0 & 1 & 5 & 2 & 4 & 0 & 24 \\
\hline Yaka Porã & $\mathrm{G}$ & 1 & 6 & 5 & 7 & 2 & 1 & 6 & 10 & 5 & 2 & 45 \\
\hline Pirai & G & 2 & 10 & 12 & 15 & 1 & 2 & 7 & 10 & 12 & 3 & 74 \\
\hline Toldo e Bugiu & $\mathrm{G}$ & 1 & 6 & 7 & 13 & 5 & 1 & 3 & 9 & 15 & 4 & 64 \\
\hline La Klano & $\mathrm{X}^{*}$ & 71 & 148 & 254 & 367 & 103 & 84 & 137 & 225 & 365 & 98 & 1852 \\
\hline Rio dos Pardos & $\mathrm{X}$ & 1 & 3 & 2 & 7 & 1 & 1 & 4 & 7 & 6 & 0 & 32 \\
\hline Total H/M & & & & 4.610 & & & & & 4.319 & & & 8.929 \\
\hline Total por faixa/he & & 166 & 602 & 1.429 & 1.974 & 439 & 174 & 556 & 1.320 & 1.840 & 429 & 8.929 \\
\hline Total Kaingang & & 68 & 331 & 971 & 1.349 & 285 & 63 & 321 & 886 & 1242 & 279 & 5.795 \\
\hline Total Guarani & & 26 & 120 & 202 & 251 & 50 & 26 & 94 & 202 & 227 & 52 & 1.250 \\
\hline Total Xokleng & & 72 & 151 & 256 & 374 & 104 & 85 & 141 & 232 & 371 & 98 & 1.884 \\
\hline
\end{tabular}

${ }^{6}$ Fontes: 1 - Fundação Nacional de Saúde. Plano Distrital de Saúde Indígena, Período: 2008-1010. Florianópolis, Santa Catarina; 2 - Cimi Sul, Florianópolis Santa Catarina. 


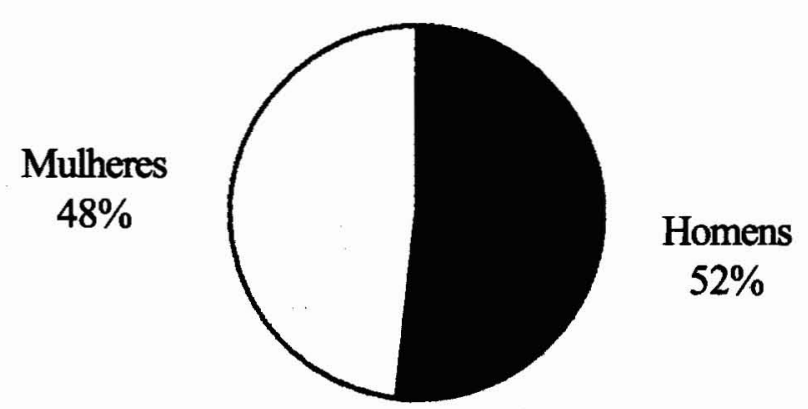

Figura 4

População indigena masculina e feminina em 2008

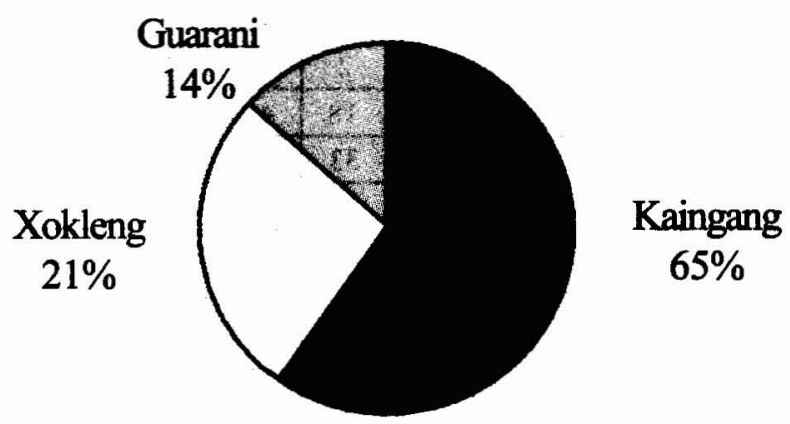

Figura 5

População por povo indígena em 2008

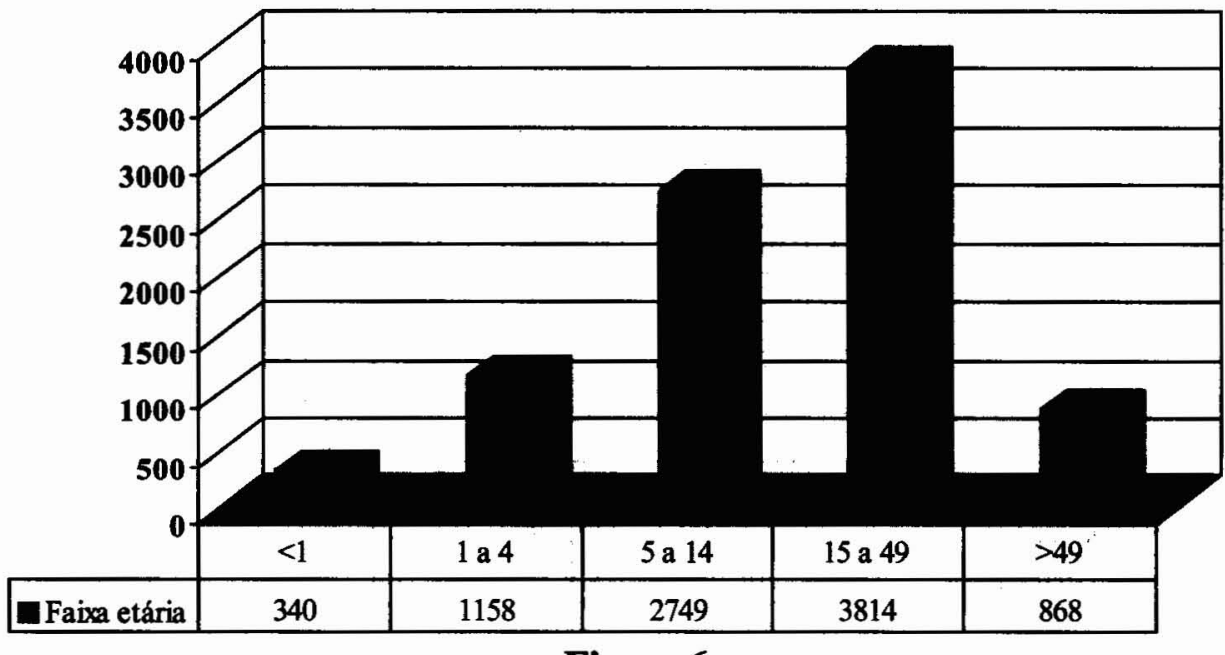

Figura 6

População indígena por faixa etária em 2008 
Demografia e direito indígena: uma leitura a partir do contexto catarinense Ana Lúcia Vulfe Nötzold e Clóvis Antônio Brighenti

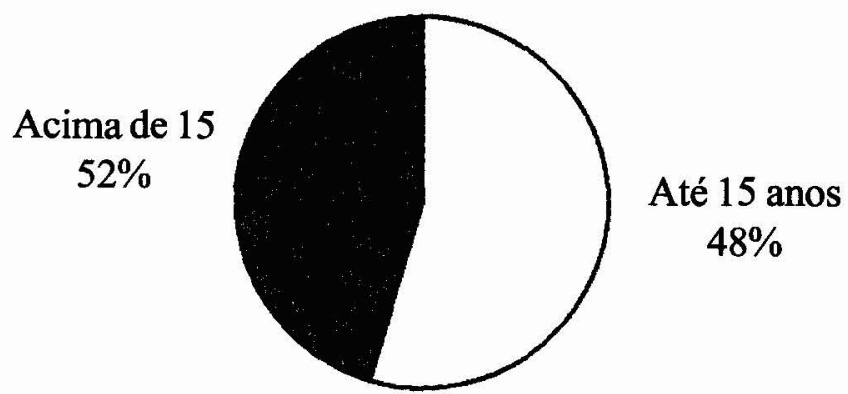

Figura 7

População indígena por faixa etária em 2008: > e < de 15 anos

Quadro3

Evolução do quadro populacional Indígena em Santa Catarina ${ }^{7}$

\begin{tabular}{|c|c|c|c|c|c|c|c|c|c|}
\hline & 1914 & $1932(\mathrm{X}) / 42(\mathrm{~K})^{*}$ & 1946 & 1951 & 1976 & 1988 & 1992 & 1998 & 2008 \\
\hline Kaingang & $\mathrm{S} / \mathrm{d}$ & 775 & 765 & \multirow{2}{*}{950} & \multirow{3}{*}{1785} & 3.000 & - & 4286 & 5795 \\
\hline Guarani & $\mathrm{S} / \mathrm{d}$ & S/d & 58 & & & 500 & - & 414 & 1250 \\
\hline Xokleng & 400 & 106 & 258 & 290 & & 1200 & - & 1480 & 1884 \\
\hline Total & & 881 & 1.081 & 1.240 & 1.785 & 4.700 & 5.235 & 6.180 & 8.929 \\
\hline
\end{tabular}

* Por não encontrarmos dados da população Kaingang no ano mais próximo ao 1932 quando temos informaç̃̃es da população Xokleng, para efeito de visualização no gráfico, optamos em somar aos dados da população Kaingang de 1944.

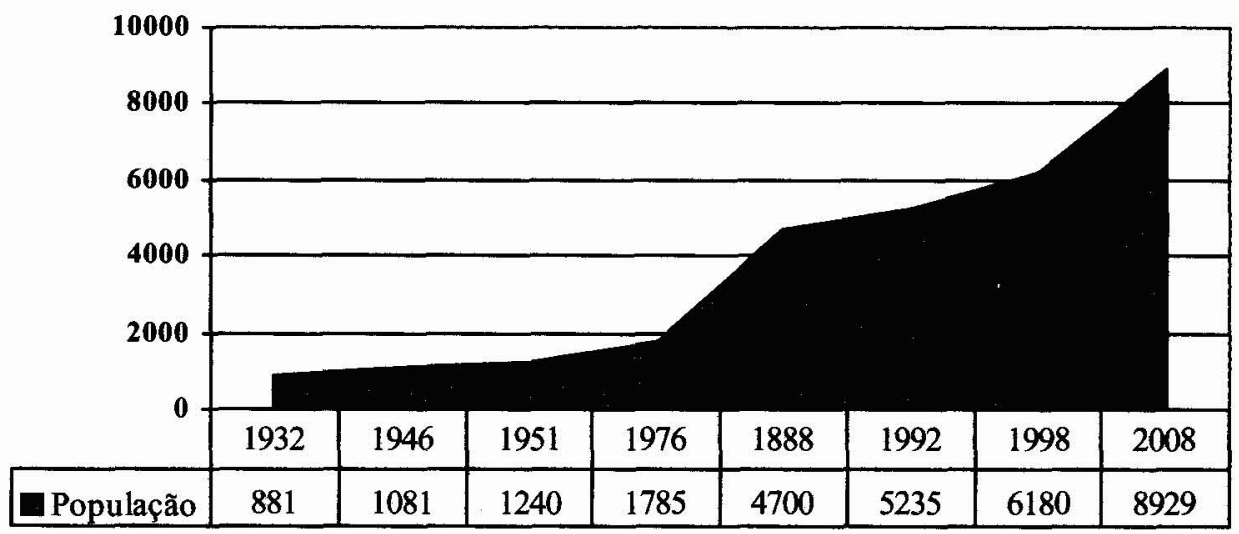

Figura 8

Evolução da população indígena em Santa Catarina

\footnotetext{
${ }_{7}$ A população brasileira era de 51,9 milhões em 1950; 70,2 milhões em 1960; 93,1 milhões em 1970 , 119 milhões em 1980; 146,8 milhões em 1990 e 157 milhões em 1996. Fonte: IBGE. Se no período de aproximadamente 50 anos a população brasileira triplicou, no mesmo período a população indígena aumentou 5 vezes.
} 
Quadro 4

Evolução das terras indígenas reconhecidas pela União ${ }^{8}$

\begin{tabular}{l|c|c|c|c|c|c|c|c|c}
\hline & 1914 & 1932 & 1946 & 1951 & 1976 & 1988 & 1992 & 2000 & 2008 \\
\hline Kaingang & 01 & 01 & 01 & 01 & 01 & 02 & 02 & 04 & 05 \\
\hline Guarani & - & - & - & - & - & - & - & 01 & 13 \\
\hline Xokleng & 01 & 01 & 01 & 01 & 01 & 01 & 02 & 02 & 02 \\
\hline Total & 01 & $\mathbf{0 2}$ & $\mathbf{0 2}$ & $\mathbf{0 2}$ & $\mathbf{0 2}$ & $\mathbf{0 3}$ & $\mathbf{0 4}$ & $\mathbf{0 6}$ & $\mathbf{2 0}$ \\
\hline
\end{tabular}

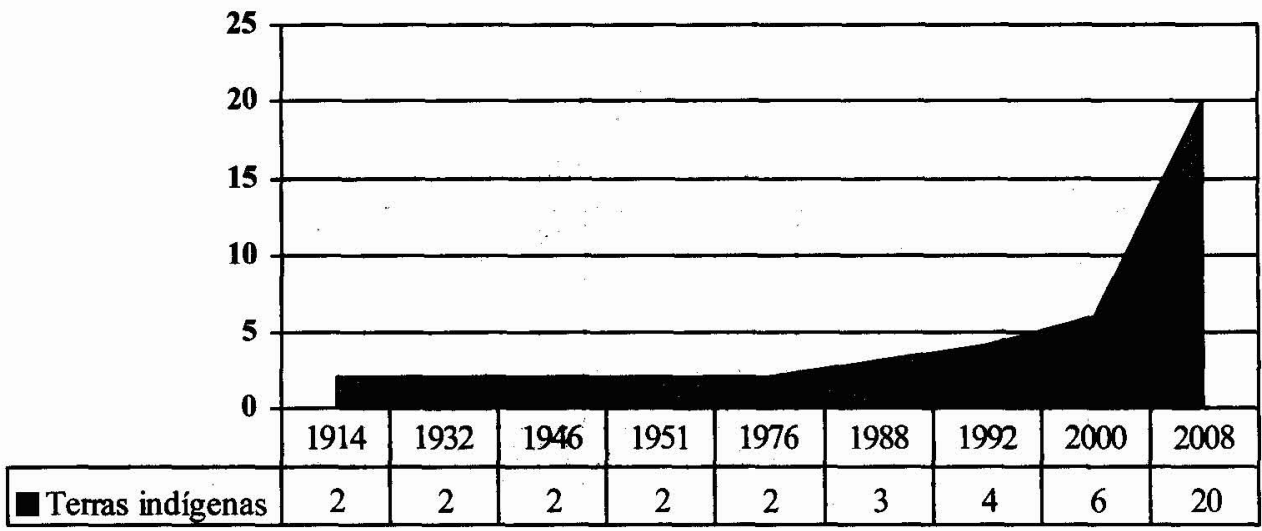

Figura 9

Evolução no reconhecimento das Terras Indígenas em Santa Catarina

\section{Demografia e direito indígena no Brasil}

No cruzamento dos dados acima, queremos salientar um aspecto que consideramos central e delimitador de práticas e posturas que modificaram o quadro populacional e fundiário em Santa Catarina. Chamamos atenção para o contexto da Constituição Federal de $1988^{\circ}$, como um marco que separa a perspectiva da transitorialidade do indígena pela via da integração e tutela,

\footnotetext{
${ }^{8}$ Consideramos reconhecidas aquelas terras que tiveram aprovado o relatório de identificação e delimitação. Para o povo Guarani há apenas uma terra regularizada; quatro terras reservadas; oito terras em processo de regularização; cinco terras sem providências e duas terras Guarani localizamse em terras Kaingang e Xokleng. Das duas terras Xokleng, uma está regularizada e a outra se encontra parcialmente regularizada; Já as terras Kaingang, quatro estão parcialmente regularizadas e uma encontra-se em fase de criação de reserva. Somando o tamanho de todas as terras reconhecidas no estado não atinge $1 \%$ (um) do território estadual para abrigar três povos.

${ }^{9}$ Nos referimos ao contexto da Constituição de 1988 e não propriamente a data de sua aprovação em 05 de Outubro, ou seja, todo movimento surgido na década de 1970 com as assembléias indígenas e a participação ativa desses povos em todo processo Constituinte. A aplicação da Lei não ocorre de forma automática e no instante de sua aprovação, mas o fator determinante nesse processo foi a participação indígena e que a partir de então continuou tendo papel ativo na aplicação das políticas públicas.
} 
para a perspectiva da autonomia e do reconhecimento da organização social. Nota-se que concomitante ao crescimento populacional há um aumento no número de terras reconhecidas.

Desde o período colonial, a prática indigenista brasileira estava voltada para a eliminação cultural através da integração do indígena à sociedade nacional. Além da supressão cultural havia também a perspectiva da eliminação física dos grupos que não aceitassem se submeter às regras coloniais. ${ }^{10}$

A partir do século XIX a questão indígena passa a ser tratada como uma questão de terras (CUNHA, 1992, p.134). Os indígenas serão menos essenciais como mão-de-obra, mas as terras que ocupam são potencialmente produtivas, gerando muitas disputas. Assim sendo, não havia dúvida quanto à promoção da "limpeza" dos sertões. O que estava em debate era o que fazer com os indígenas resistentes. Havia os que defendiam a simples eliminação para desinfestar os sertões, outros que defendiam a incorporação na comunhão nacional. Para os estadistas a segunda alternativa parecia mais viável, embora na prática prevalecesse a desinfestação. Cunha (Idem) argumenta que "este debate, cujas conseqüências práticas não deixam dúvidas, trava-se freqüentemente de forma toda teórica, em termos da humanidade ou animalidade dos índios".

O indígena "bravo" que deveria ser eliminado era o Tapuia, nome genérico dado aos indígenas não tupi. Foram considerados Tapuias os Botocudos ou Xokleng que viviam no leste do estado de Santa Catarina, os Borum e outros grupos do leste e nordeste de Minas Gerais, cujos descendentes são hoje os Krenak e os Kaingang dos campos sulinos e oeste de São Paulo. Para o Império brasileiro os indígenas da costa, como os Guarani, já estavam extintos ou integrados; apareciam apenas na literatura, poesia e na arte brasileira, como uma autoimagem do Brasil. É o índio caricaturado, dos monumentos e alegorias. Todavia os Botocudos ainda estavam presentes, uma presença incômoda para as pretensões brasileiras de ocupação dos sertões. A distinção entre Botocudos e TupiGuarani também se fazia presente na política de definição de terras. Enquanto que para os Botocudos foi necessário reservar alguns espaços mínimos de terra, para confina-los e assim afasta-los das frentes de ocupação, o Guarani foi ignorado em sua realidade e em sua condição incômoda de indígena.

\footnotetext{
${ }_{10}$ Moraes (2000, p. 384), comenta que a Guerra do Açu, entre 168 e 1704, "bem exemplifica uma nova orientação adotada pelos colonizadores em face das populações autóctones: não mais a escravização ou a tentativa de integração como meta, mas a eliminação como objetivo explícito das ações".
} 


\section{HÜMANAS}

Considerados “incorporados" já não se fazia necessário garantir terras para sua sobrevivência. A primeira terra Guarani em Santa Catarina vai ser reconhecida oficialmente apenas em $1999^{11}$.

A política indigenista ${ }^{12}$ adotada pelo Estado brasileiro, já no final do século XIX início do século XX, tinha por objetivo desobstruir as terras dos temíveis Botocudos, liberando-as para os colonos e, conseqüentemente resolvendo "o problema índio". O Brasil passava a ser uma única nação, impondo uma política com dois aspectos básicos: a tutela ${ }^{13}$ e a integração.

Em relação ao poder tutelar, Lima (1995, p.43) comenta que era:

[...] uma forma reelaborada de uma guerra, ou, de maneira muito mais específica, do que se pode construir como um modelo formal de uma das formas de relacionamento possível entre um "eu" e um "outro", afastado por uma alteridade (econômica, política, simbólica e espacial) radical, isto é, a conquista, cujos princípios primeiros se repetem - como toda repetição, de forma diferenciada - a cada pacificação.

Essa guerra, a que se refere Lima, era a estratégia da administração, que visava "sedentarizar" povos considerados errantes, que resistiam a fixação em lugares previamente definidos, onde seriam doutrinados pela administração oficial. Mas o poder tutelar não seria perpétuo, estava previsto um término que ocorreria quando os povos indígenas estivessem incorporados à comunhão nacional.

A tutela se convertia em atitudes e práticas políticas,

[...] o melhor produto da dinâmica tutelar seria, talvez, a figura das reservas indígenas, i.é.,

\footnotetext{
"Trata-se da TI M'Biguaçu, demarcada com 59 ha através da Portaria Ministerial n 613, de 35 de Julho de 2000.

12 Para efeito deste artigo, definimos Política Indigenista como sendo todas as ações do Estado brasileiro para os povos indígenas. Esta ação vista a partir do distanciamento entre a legislação vigente e sua aplicação num determinado contexto histórico.

${ }^{13} \mathrm{O}$ Art. $6^{\circ}$ do Código Civil Brasileiro (Lei n..$^{\circ} 3.071$, de $1^{\circ}$ de Janeiro de 1916, com as correções ordenadas pela Lei n. $^{\circ} 3.725$, de 15 de Janeiro de 1919) Diz: São incapazes, relativamente a certos atos (art. 147, n. ${ }^{\circ}$ ), ou à maneira de os exercer: III - os Silvícolas. Parágrafo Único. Os silvícolas ficarão sujeitos aos regime tutelar, estabelecido em leis e regulamentos especiais, o qual cessará à medida que se forem adaptando à civilização do país.
} 


\title{
Demografia e direito indígena: uma leitura a partir do contexto catarinense Ana Lúcia Vulfe Nötzold e Clóvis Antônio Brighenti
}

\begin{abstract}
porções de terras reconhecidas pela administração pública, através de seus diversos aparelhos como sendo de posse de índios e atribuídas, por meios jurídicos, para o estabelecimento e a manutenção de povos indígenas específicos (Idem, p.76).
\end{abstract}

Na tutela está a fundamentação para a manutenção do viés da integração indígena à comunhão nacional. Os povos indígenas eram considerados como grupos transitórios. A criação de reservas indígenas e toda a estrutura de "proteção", como Posto, Escola e Igreja era considerada apenas uma etapa no processo evolutivo que culminaria com o seu desaparecimento. Os indígenas passariam por etapas de humanização, através da religião católica e a educação escolar, até atingir um patamar superior considerado "civilização". Essa interpretação é destacada por Cunha (1992, p. 135) ao afirmar que "no século XX, outra variante ainda desse mesmo ideário seria a crença na inexorabilidade do 'progresso' e no fim das sociedades indígenas". Para dar conta dessa política é criado em 1910, um órgão federal, o Serviço de Proteção aos Índios e Localização de Trabalhadores Nacional -(SPILTN), que mais tarde, em 1918, lhe seria subtraída a tarefa de Localização de Trabalhadores Nacional (SILVA, 1996, P.295), ficando apenas com Serviço de Proteção aos Índios - SPI.

As duas reservas indígenas criadas em Santa Catarina no início do século XX, na perspectiva do Serviço de Proteção aos Índios, eram suficientes para abrigar a população que se encontrava pelo estado, assim está expresso no documento do Inspetor Souza Nenê (Ibid) ao referir-se aos Kaingang que se encontravam nas margens do rio Irani: "porém estes o S.P.I. procurará transferir para as terras do Xapecó" [referindo-se a Reserva Xapecó]. Relatos Guarani indicam que havia diversas aldeias pelo estado, mas não eram assistidos, porque a assistência pressupunha o prévio confinamento na Reserva:

Então como fiz, cheguemos aqui em Florianópolis, em 1968. Cheguemos em Florianópolis e fiquemos três dias. Dentro de três dias apareceu um homem de gravata, num fusca, aí perguntou pra mim o que é que eu tava fazendo, se tava passeando. Digo, tamo paseando. 


\section{HÜMANAS}

E: -o que que você queria? Eu queria uma paradinha por aí... vê se arrumava um lugarzinho pra dá uma parada". - Por aqui não tem lugar. O lugar do índio é em Ibirama [possivelmente referindo a reserva indígena Ibirama] (destacamos). Então hoje e amanhã você pede alguma coisinha, ganha alguns trocadinho pra passagem por aqui, se encaminha lá pra Ibirama". - Ma... Má será que não podemos passear nada, o pobre não pode passear? Mas esse mundo foi feito sem porteira!". Ai ele me falou que não pode me responder isso, por causo que - não sou delegado (NUNES, 1999).

Nas Reservas os mecanismos de repressão eram aplicados para coibir qualquer tentativa de manifestação contrária a administração ou a prática adotada. Nacke (2007, p.52) destaca que:

[...] mecanismos de repressão que passaram a fazer parte do cotidiano das famílias indígenas. Dentre outros pode-se mencionar a prática da transferência compulsória de indivíduos para outras TIs, o que implicava no rompimento de redes de parentesco e solidariedade existentes na terra de origem, bem como a perda da moradia e das terras em que plantavam.

Com o fim do Serviço de Proteção aos Índios e a criação da Fundação Nacional do Índio (Lei n 5.371 de 05 de Dezembro de 1967), essa perspectiva da integração dos povos indígenas continuou inalterada e foi externada com maior precisão na Lei $N^{\circ} 6.001$, de 19 de Dezembro de 1973, que dispõe sobre o Estatuto do Índio.

Art. $1^{\circ}$ - Esta Lei regula a situação jurídica dos índios ou silvícolas e suas comunidades indígenas, com o propósito de preservar a sua cultura e integrá-los, progressiva e harmoniosamente à comunhão nacional. 


\section{Demografia e direito indígena: uma leitura a partir do contexto catarinense}

Ana Lúcia Vulfe Nötzold e Clóvis Antônio Brighenti

[...] Art. $4^{\circ}$ - Os índios são considerados:

I - Isolados - Quando vivem em grupos desconhecidos ou de que se possuem poucos e vagos informes através de contatos eventuais com elementos da comunhão nacional;

II - Em vias de integração - Quando, em contato intermitente ou permanente com grupos estranhos, conservam menor ou maior parte das condições de sua via nativa, mas aceitam algumas práticas e modos de existência comuns aos demais setores da comunhão nacional, da qual vão necessitando cada vez mais para o próprio sustento;

III - Integrados - Quando incorporado à comunhão nacional e reconhecidos no pleno exercício dos direitos civis, ainda que conservam usos, costumes e tradições características da sua cultura (FUNAI, 2003, p. 47).

Percebe-se que havia uma contradição na sua formulação, pois a preservação da cultura e a integração contrapõem-se e não podem ser desenvolvidas conjuntamente, conforme diz o texto. A tutela permaneceria em vigor, não tendo efeito sobre os indios integrados: "Art. $7^{\circ}$ - Os índios e as comunidades indígenas ainda não integrados à comunhão nacional ficam sujeitos ao regime tutelar estabelecido em lei" (Ibid, p.49).

A Constituição Federal de 1988 alterou radicalmente as diretrizes legais do relacionamento do Estado brasileiro com os povos indígenas. Embora a Constituição Federal não explicite o termo "Povos Indígenas", pelo texto aprovado, fica clara essa perspectiva ao reconhecer a organização social, costumes, línguas crenças e tradições e os direitos originários sobre as terras que tradicionalmente ocupam. A Constituição de 1988 dedicou um capítulo específico aos indígenas, além de várias referências no próprio texto constitucional.

Com esse novo texto foi eliminada a tutela, aferida no Código Civil de 1919, e confirmada no Estatuto do Índio (Lei 6001/73), fixando-se novos marcos para constituição de um estado democrático, onde os povos indígenas não estão mais coagidos a se integrarem na cultura dominante. 


\section{HUMANAS}

Essa Constituição rompeu com os textos constitucionais anteriores $\mathrm{e}$ com as práticas adotadas desde $\mathrm{o}$ Brasil colônia. Podemos considerar essa Constituição como um divisor claro e profundo entre a perspectiva da transitorialidade dos povos indígenas para uma perspectiva de reconhecimento $\mathrm{e}$ respeito às culturas diferenciadas $\mathrm{e}$ as identidades próprias. Com isso o Brasil se reconhece com um Estado pluricultural, "admite e reconhece a coexistência de várias nações no Estado brasileiro"'(GUIMARÃES, 1999, P.546). ${ }^{14}$

As Terras Indígenas adquirem outro significado e apontam para a necessidade da garantia de espaço suficiente. Se a Lei 6001/73 enfatizava a via camponesa como forma de integrar o indigena à comunhão nacional e concebia a terra como meio de produção necessário, a Constituição de 1988 identificou o conceito de terra indígena como o de habitat, ao contrário dos textos anteriores onde a noção de ocupação indígena se assemelhava ao conceito civil de posse. $O$ sentido das terras como cercos da paz, agora deverão ser pensadas como habitat, espaços da vivência da identidade e, portanto não mais transitórios, mas permanentes. Isso significa que são reconhecidas não apenas as áreas de habitação permanente, mas todo o espaço necessário à manutenção das tradições do grupo. Segundo Oliveira (1998, p.45):

A noção de habitat aponta para a necessidade de manutenção de um território, dentro do qual um grupo humano, atuando como um sujeito coletivo e uno, tenha meios de garantir a sua sobrevivência físico-cultural. E acrescenta: a Constituição Federal de 1988 conceitua como "indígenas" todas as terras que constituem objeto de "uso ou ocupação tradicional (isto é, segundo seus usos e costumes) por coletividades indígenas. Isso corresponde a um deslocamento das discussões legais do plano da antigüidade para a forma de ocupação.

\footnotetext{
$14 \mathrm{Na}$ opinião do geógrafo Alfredo Wagner Berno de Almeida (2004, p. 09) a tutela não foi totalmente extinta, uma vez que as terras indígenas continuam sendo bens da União. Os preceitos evolucionistas de assimilaça dos "povos indígenas e tribais" na sociedade dominante foram deslocados pelo estabelecimento de uma nova relação jurídica entre o Estado e estes povos, com base no reconhecimento da diversidade cultural e étnica. No ato das disposiçøes constitucionais transitórias foi instituída, também, consoante o Art.68, nova modalidade de apropriação formal de terras para povos como os quilombolas baseada no direito à propriedade definitiva e não mais disciplinada pela tutela, como soa acontecer com os povos indígenas.
} 
Demografia e direito indígena: uma leitura a partir do contexto catarinense Ana Lúcia Vulfe Nötzold e Clóvis Antônio Brighenti

Segundo Guimarães (Ibid, p.547), as terras indígenas definidas como bens da coletividade do país,

[...] qualquer cidadão tem legítimo interesse jurídico na proteção das terras indígenas. Além do aspecto humanitário da obrigação de todos respeitarem a diversidade étnica, o tratamento das terras indigenas como bens da União remete à circunstância de tratar-se de objeto cuja segurança atinge a todos no País.

\section{Algumas reflexões complementares}

A partir dos dados da população indígena em Santa Catarina é possível afirmar que o aumento populacional está diretamente relacionado ao fim do regime tutelar e o reconhecimento da organização social. Concomitante ao aumento populacional está o aumento na demanda por terras. Em 1981 a Funai divulgou um quadro com a "distribuição das Terras Indígenas por Condição de Demarcação e por Unidade Administrativa da FUNAI" (OLIVEIRA, 1998, p.44), em que Santa Catarina aparece resolvida a demarcação das terras. Porém, a realidade atual é totalmente outra, visualiza-se uma nova realidade, de muitas demandas por terras e procedimentos administrativos em andamento.

A conquista de direitos teve reflexo também nas políticas assistenciais e nas condições de sustentabilidade. $O$ fim da tutela significou também a possibilidade de maior controle por parte dos indígenas sobre o atendimento a saúde, exigindo cada vez mais uma política diferenciada, conquistada através de um subsistema específico. A prática ainda significa desafios a serem superados, políticas a serem melhoradas, todavia os avanços até o momento são significativos. A conquista de novas terras também significou avanços na sustentabilidade, mas esse aspecto carece uma análise mais detalhada.

Constata-se que há um crescimento vegetativo significativo, mas paralelo a isso há uma maior visibilidade, fruto de afirmação da identidade expressa na relação de alteridade, bem como na concepção de cidadania. Indivíduos e comunidades que não eram consideradas pelas estatísticas conquistaram direito e adquiriam visibilidade e iniciaram um processo de reconquista das terras, ou seja, afirmaram o desejo de viver a seu modo em espaços próprios. 


\section{UMANAS}

\section{Referências bibliográficas}

ALMEIDA,A. W. B. Terras tradicionalmente ocupadas: processos de territorialização e movimentos sociais. Revista Brasileira de Estudos Urbanos e regionais, v.6, n.1, p. 09-32, Maio. 2004.

CIMI SUL - Conselho Indigenista Missionário Regional Sul. Informativo Luta Indígena. Ano 01. n. 02. Xanxerê - Santa Catarina. Maio. 1976.

CIMI SUL - Conselho Indigenista Missionário Regional Sul. Boletim Cimi Sul, n. 25. Xanxerê-Santa Catarina. Junho.1988.

CIMI SUL -Conselho Indigenista Missionário Regional Sul. Relatório de avaliação regional. Chapecó - Santa Catarina. 1998.

CIMI SUL - Conselho Indigenista Missionário Regional Sul. Relatório de avaliação regional. Equipe Florianópolis. Florianópolis-Santa Catarina. 2008.

CUNHA, M. C. Política Indigenista no Século XIX. In: CUNHA, Manuela Carneiro da. História dos índios no Brasil. São Paulo: FAPESP/SMS/Companhia da Letras, 1992.

DOS ANJOS, P. V. P. Relatório sobre os índios em Santa Catarina. Relatório. Chapecó, março de 1992.

FORTES, F. S. Posto Indígena Xapecó. Quadro da população indígena. 1944.

FORTES, F. S. Posto Indígena Xapecó. Quadro da população indígena. 1948.

FUNAI - Fundação Nacional do Índio Administração Executiva Regional Curitiba. Quadro demonstrativo das terras indigenas assistidas pela AER Curitiba. Relatório. Fev 1998

FUNASA, Fundação Nacional de Saúde. Plano Distrital de Saúde Indígena: Período: 2008-1010. Florianópolis, Santa Catarina; 2008.

GUIMARÃES, P. M. Proteção legal das terras indígenas. In. LARANJEIRAS, Raimundo. Direito agrário brasileiro. São Paulo: LTR, 1999.

HENRIQUES, K. N. R. Territórios indígenas em espaços urbanos: um estudo da migração dos indígenas da TI Ibirama para Blumenau - Santa Catarina. 2000. Dissertação (Mestrado em Antropologia Social) - Curso de PósGraduação Antropologia Social, UFSC. Florianópolis. 
IBGE - Instituto Brasileiro de Geografia e Estatísticas. Brasília-DF, 2000. Disponível em : http://www.ibge.gov.br/home/estatistica/populacao/ defaulttab_amostra.shtm

LIMA, A. C. S. Um grande cerco da paz. Poder Tutelar, indianidade e formação do Estado no Brasil. Petrópolis: Vozes, 1995.

MORAES, A. C. R. Bases da formação territorial do Brasil: o território colonial brasileiro no "longo" século XVI. São Paulo: Hucitec, 2000.

NACKE, A. e BLOEMER, N. M. S. Áreas indígenas Kaingang no Oeste de Santa Catarina. In; NACKE, A. et alli.: Os Kaingang no Oeste Catarinense. Tradição e atualidade. Chapecó: Argos, 2007.

NOTZOLD, A. L. V. Nosso vizinho Kaingáng. Florianópolis: Imprensa Universitária, 2003.

NUNES, H. Entrevista concedida a Clovis Antonio Brighenti. Massiambu (SC). Em 18 de novembro de 1999.

OLIVEIRA, J. P. Redimensionando a questão indígena no Brasil. In: OLIVEIRA, J. P. Indigenismo e territorialização. Rio de Janeiro: Contra Capa, 1998.

Revista do Museu Julio de Castilhos e Arquivo Histórico do Rio Grande do Sul. ano. 7, n.8, p. 108-132. 1957.

SANTOS, S. C. A Integração do índio na sociedade regional. A função dos Postos Indígenas em Santa Catarina. Florianópolis: Imprensa Universitária da UFSC, 1970.

SANTOS, S. C. Índios e brancos no sul do Brasil: a dramática experiência Xokleng. Florianópolis: Edeme, 1973.

SILVA, L. O. Terras devolutas e latifúndio: efeitos da Lei de 1850. Campinas, SP: Editora da UNICAMP, 1996.

SOUZA N, e SOUZA, D. Exmo. Snr. Governador do Estado de Santa Catarina. Relatório da $7^{\mathrm{a}}$ Inspetoria Regional do Serviço de Proteção aos Índios ao Governador do estado de Santa Catarina. Curitiba (PR). 1951. 